\title{
Licensed Lenders' Services to Indonesian SMEs: 'Mystery Shopping' Results
}

\author{
Raymond J. Struyk (corresponding author) \\ NORC at the University of Chicago \\ 4350 East-West Highway, Bethesda, MD 20814 \\ Tel: 1-301-634-9434Ｅ-mail: Struyk-Ray@norc.org \\ Samuel R. Haddaway \\ NORC at the University of Chicago \\ 4350 East-West Highway, Bethesda, MD 20814 \\ Tel: 1-301-634-9423Ｅ-mail: Haddaway-Samuel@norc.org
}

Received: September 10, $2010 \quad$ Accepted: December 21, $2010 \quad$ doi:10.5539/ijef.v3n3p3

This researched is financed by NORC and the International Finance Corporation.

\begin{abstract}
Formal Indonesian lenders see small firms in particular as the main opportunity for expanding their financial services business. How does this translate into the experience of a small firm owner who applies for a loan? This question is addressed by 52 "mystery shopping" visits to 26 lenders in the Jakarta region. Three areas are investigated: service quality, competition and cross selling. The results show that service quality has significant room for improvement. While there is considerable scope for competition among lenders, with substantial variation across banks in terms of products offered and loan requirements, there is very little variation within a bank branch, i.e., most banks offered just one product to the customer. Very little cross-selling is done, indicating a real opportunity for improvements in service. Overall, the lack of proactive service by lenders places the burden of identifying superior financial products squarely with small firms.
\end{abstract}

Keywords: SMEs, Credit, Indonesia, Commercial lenders

\section{Introduction}

The informed view in Indonesia is that commercial banks need to expand lending to small firms and use this as a bridge to selling other banking services. The large-firm credit market is highly competitive with thin margins. Medium firms' credit needs are also comparatively well-met, banks having expanded some years ago into this market. To grow lending volumes, a principal market is small firms (e.g., International Finance Corporation 2007). (Note 1) Major banks and non bank financial institutions (NBFIs) are moving in this direction.

In a recent survey undertaken as part of the project that produced the data reported here, lenders stated that they were undertaking a series of initiatives to expand their business with small and medium firms. The list of actions cited is impressive. In part this can be explained by the emphasis that the Indonesian government has placed on expanding credit availability to SMEs (Godau et al. (2004), chapter 3); but it also part of lenders' own strategies. A critical question is the extent to which this emphasis has filtered down to front line bank officers in terms of the service they provide to small firm clients. This article reports the results of 'mystery shopping' for a loan at these lenders by a person posing as the owner of a small firm.

Past studies indicate that obtaining finance is a problem for Indonesian SMEs (Bank Indonesia 2005, DAI 2004, Asia Foundation 2005). Most relevant for our purposes is the DAI study that focused on small and medium firms in East Java. The survey found that 19 percent of SM firms rated finance as a "principal problem" and another 16 percent as a secondary problem. While substantial, these are in a distant second place behind "market problems," i.e., insufficient demand or too much competition, which half of all respondents cited in both categories.

The same survey inquired about wider banking services. Eighty-one percent reported having a savings or deposit account, 58 percent using the bank to send or receive funds, and 57 percent an ATM card. The incidence of business loans was only 34 percent. Respondents were also asked to identify the "most helpful" banking services. The top four 
services were: a savings or deposit account (rated most helpful by 30 percent of respondents), an ATM card (24 percent), sending and receiving transfers (21 percent), and business loans (12 percent). The priority of non credit services is striking. Cross selling products has clear potential.

Mystery shopping is the process of someone posing as a client to learn how clients are being treated by the staff of the firm being investigated. The technique is commonly used by retail firms, including banks, to monitor the quality of their services. Mystery shopping has been employed in two quite different forms in retail banking. One has been the straightforward use of mystery shoppers to measure the quality of services provided to customers seeking different banking service types (Roberts and Campbell (2006) and Schrader (2006)). The other compares differences in treatment. It employs paired shoppers of different races or other characteristics to determine if commercial banks discriminate against some types of customers. For example, a black person inquires about a loan and receives information, and then a white person with the same profile and behavior does the same. After the interview, each independently completes a form detailing what he was told and how he was treated. The information on the two forms is compared to determine differences in treatment. Many paired tests can provide reliable evidence of discrimination. (An example of paired tests measuring discrimination in mortgage lending is Turner et al. (2002).)

The objective of the mystery shopping conducted for this study was to gather information in three areas on Indonesian lenders' branches:

1. The quality of service provided by loan officers and other staff at commercial bank branches

2. The relative competitiveness of banks in offering loan products to a particular type of borrower for the same purpose, and

3. The extent to which the loan officer or other staff meeting with the client tried to cross-sell other products to the client.

Tests were conducted at 26 financial institutions including 20 commercial banks, 2 cooperatives, 2 rural banks (BPRs), and 2 multi-finance companies. (An overview of the Indonesian financial market is presented in International Finance Corporation (2006).) One test was conducted at each of two branches for each included institution, for a total of 52 tests. Two tests were done for each bank to provide a more reliable service profile. The shopper visited the selected branch offices without an appointment to discuss his loan, i.e., he was a "walk-in" applicant. This is common practice in Indonesia.

To our knowledge this is the first study of the treatment of an SME borrower by staff at a substantial sample of formal lenders in one country.

The balance of this article consists of four sections. The next describes the mystery shopper's firm and the loan the firm was seeking at each bank. Section 3 outlines how the three service dimension listed above were operationalized. Section 4 presents the results and the final section offers conclusions.

\section{Firm and Loan Profile}

One scenario was developed and one shopper performed all bank visits. In running tests on comparable banks, it is critically important to minimize the sources of variation in interview outcomes so that one is confident that the differences among banks are attributable strictly to the loan or other officer with whom the shopper met and the bank's policies, and not to a combination of loan officer differences, the particulars of the loan requested, the firm inquiring about the loan and how the shopper presents himself. While strong training can minimize the differences arising from interviewer variance, use of a single interviewer has the clear advantage of consistency.

\subsection{The 'Firm's' Profile}

The scenario is of a small laundry with a dozen employees whose owner is seeking a loan to expand its operations by acquiring an additional washing machine, dryer, and delivery vehicle. A laundry was selected because they are ubiquitous in urban Indonesia.

The firm is classified as "small" using current Bureau of Statistics definitions, i.e., in the year preceding the loan inquiry, the firm's turnover was just over INR 300 million. (The exchange rate in summer 2009 was about INR10,000 $=1$ USD.) The profile developed includes financial statements, staff listing, its banking relations, a list of licenses and documents possessed by the firm, and other information. This detailed information was not provided or even shown to the loan officer during the interview, but it formed a deep basis for the shopper to draw upon in responding to loan officer questions. Because this was an initial inquiry about a loan, detailed information would not be essential and was not provided.

The cost of the equipment to enlarge operations was estimated at INR 92 million and 80 percent of this amount (just under INR 60 million) was requested as a loan. The expansion cost and loan amount were tailored to the laundry's 
financial profile so that it would qualify for a loan following standard lending practices. This was done to increase the likelihood that a full interview would be completed.

The team member who prepared the scenario and did the interviews has his own small enterprises. He has taken out loans for a micro business and for his personal car and home purchases. There was extensive training on the need for consistency across interviews and in completing the post-interview form.

\subsection{Reporting Form}

A form was developed to capture the information provided by the loan officer and others with whom the shopper dealt; the location where the interview was held, particularly if it was a private space; which information was volunteered and which had to be requested; the details of the various loan products offered and which, if any, was recommended; whether there was any follow-up by the loan officer following the interview; and, the extent to which the shopper was offered additional products and services. This form was completed immediately after the interview in a private place away from the bank.

\section{Measuring Service Quality}

As noted, the 'mystery shopping' tests were organized to learn about lender branch staff behavior in three areas: the quality of services provided, the competitiveness of the bank's loan offer, and the extent of cross-selling that occurred. This section discusses how behavior in these three areas was measured.

\subsection{Service quality}

A widespread approach to measuring service quality in a retail environment is SERVQUAL. (The original development of the procedure was by Parasuraman, Zeithaml, and Berry (1988); an overview discussion of the validity of the technique is in Newman (2001).) It has the five dimensions listed below and there is a set of indicators defined for each dimension.

1. Assurance - knowledge and courtesy of employees and their ability to convey trust and confidence.

2. Tangibles - appearance of physical facilities, equipment, personnel and communications materials.

3. Empathy - level of caring, individual attention provided to customers.

4. Responsiveness - willingness to help customers and provide prompt service.

5. Reliability - ability to perform the promised service dependably and accurately.

This structure has been used successfully in analyses of retail banking operations in industrial and developing countries as well as retail trade and services providers (Newman and Cowling (1996), Newman (2001) and Marshall and Smith (1999).) See Angur et al. (1999) for an application in India.

We use the SERVQUAL paradigm as a general structure for conceptually organizing the mystery shopping study. That is, because these dimensions have been demonstrated to be important in measuring client satisfaction, we used them as a check list of topics to cover in developing the scenario that the shopper followed during the interviews and in defining the content of the post-interview report he completed. We did not include the reliability dimension because there was no opportunity to observe actual behavior. (Note 2)

Variables were created from the information on the post-interview recording form to measure the experience in each of the four SERVQUAL areas shown in Table 1: assurance, tangibles, empathy, and responsiveness. Except where indicated to the contrary, all variables take the value of 1 if the condition is met, e.g., the shopper met with a loan officer or equivalent (the first variable under assurance) and is zero otherwise. Values of 1 indicate better performance than zeros.

The variables under assurance concern whether the appropriate type of bank staff met with the loan client and how knowledgeable the person appeared to be.

Tangibles focus on meeting in an appropriate space (one that was sufficiently private that others would not hear the client's business details) and the kinds of materials that were given the client without the client having to ask for them. It also includes the number of loan officer counters present in the branch, which is related to but somewhat different from the information captured in waiting time (included under empathy).

The central empathy indicators address how friendly the loan officer or other bank official was in dealing with the client as indicated by an array of indicators, e.g., the time the client had to wait, the amount of time the officer spent with the client, and whether a business card or other document containing contact information was given the client. 
Several indicators of responsiveness are designed to measure how interested the bank officer was in this applicant — did he ask the essential questions or did the client have to keep feeding the officer information to advance the discussion? Also, did the officer ask the client to complete an application and/or offer to help him fill it in?

\subsection{Competition}

These indicators, employed in Table 2, concern how competitive the bank officer was in trying to get the client's business. "Competitive" here means how accommodating the loan terms were broadly defined, i.e., how many documents would have to be provided and how many different products were discussed. The first two sets of variables measure (a) whether the client was simply told that he would not qualify for a loan and (b) the various loan requirements that were discussed. The rest of the indicators measure specific attributes of the loan products offered. Because the same client requested the same loan in all cases, these results should provide excellent indicators of the possibilities for borrowers to improve loan terms by shopping around.

\subsection{Cross Selling}

Expanding business relations with small and medium sized firms beyond loans and lines of credit transactions, savings, and insurance products is extremely important for financial institutions to maximize the profitability of business with firms. The form completed by shopper after the interview prompted him to report on cross-selling for the seven different product types. The form differentiated between two intensity levels for cross-selling: "talked about it" and "Really tried to interest you in it." The two sets of variables in the panel repeat the differentiation.

\section{Findings}

The findings presentation follows the same three-part topic structure as the previous discussion. It is worth noting that because this is the first study of its type we do not have benchmarks from other studies to use to comparison. Instead, our interpretation of the mystery shopper experience relies primarily on expectations formed through discussions with knowledgeable Indonesians and informed views about good business practices.

\subsection{Service quality}

The basics are displayed in Table 1. The first column shows the mean values for all indicators with 0 or 1 scores and the percentage distributions for continuous measures. Recall that "1" always indicates better service. These are computed with the sample of 52 tests. In principle, the values for the $0 / 1$ indicators should be very near 1.00 , i.e., good service should be essentially universal. The last two columns give the number of lenders with strong and poor service. Strong service means that both branches displayed the more desired service level and poor service indicates that both branches provided services at the lower standard.

The figures on 'assurance' in the first table panel show moderately high scores. Somewhat surprisingly, the client/tester met a specialized SME loan officer only 40 percent of the time. Further, only 75 percent of the loan officers impressed the tester as having a strong knowledge of the loan products he was discussing. The low share of tests involving dealing with an SME expert suggests an opportune area for increased competitiveness in branch services provided; the apparent lack of knowledge on loan products is troubling and may point to deficiencies in training programs.

There are some issues in terms of the 'tangibles' measured (second table panel).

- In 12 percent of cases the tester did not meet in a private space with the bank officer - thereby requiring the tester to discuss the specifics of his business where the conversation could be monitored by others. This could easily discourage a borrower from returning to apply for the loan.

- In a similar share of cases the bank officer did not offer the tester a loan brochure without being prompted. This is surprising since it is a cheap and easy service to perform.

- Only 13 percent of bank officers provided a copy of the loan application without the tester asking for it. This is hard to understand since a client having specific knowledge of the information required in the application would permit him to return more ready to make his application and the process would be much more efficient for both the bank and the borrower.

The branches visited by the tester differ sharply in the number of loan counters present. Of course, these figures must be interpreted in light of the volume of customers seeking loan services at a branch. One branch had none, and the officer met the client at a desk as the alternative. Twenty-five percent have only one counter, suggesting that waiting can be a problem for clients or that there are not many clients. Another quarter of branches have four or more, indicating stronger service, holding other factors constant. (See further discussion below.) 
The information on waiting time and on time spent with the bank officer yields more favorable results. In half the branches the time waiting to see a bank officer on a "walk in" basis was 5 minutes or less. In only 17 percent of the cases did the tester wait over 10 minutes. These figures indicate that the small number of loan counters in many branches may not be a serious problem. Note, however, we have not controlled for the time of day when the tester visited the branch. (Note 3)

Like the 'tangibles' section, the 'empathy' section indicates room for improvement. While essentially all bank staff welcomed the tester in a reasonable way, only about 80 percent provided a business card or contact information in another form without being asked - an action that we believe should be performed 100 percent of the time. Absence of this contact information clearly makes it harder for the client to continue a discussion with the same bank officer. Moreover, only about 70 percent of officers were rated as being really friendly. Finally, in a real service breakdown, essentially no one offered to help the tester complete the loan application if he needed help when applying.

The tester always spent a reasonable amount of time with the bank officer-a minimum of 18 minutes and in a few cases more than 45 minutes. The majority spent a half hour or more discussing the possible loan. But the variance in time spent is large, and a borrower doing comparative shopping might feel rushed with an interview lasting under 20 minutes considering interviews typically lasted much longer.

Further issues appear when we consider the indicators in the 'responsiveness' block. Remarkably, only about 80 percent of bank officers asked about the amount of the loan being sought and the purpose of the loan. A mere 20 percent asked basic questions about the applicant's firm. In only one case did the bank officer show initiative in asking the tester to complete the application, i.e., to move ahead with the transaction; and in no case did the bank officer try to arrange for a follow-up contact.

That said, two-thirds of bank officers did convey a genuine interest in making the loan, as perceived by the shopper. Also, about 75 percent strongly recommended a specific product while 10 percent steered the tester away from a product. Overall, the findings paint a mixed picture, but it appears that a significant share of officers just go through the motions when meeting with clients from small enterprises.

We can examine the quality of service from a bank's perspective by asking in how many cases both branches scored well on these service items. Data in the last two table columns show the number of lenders out of 26 with strong or poor service ratings. There are a number of areas of strength, where at least a simple majority of banks offered strong service. For the 'assurance' indicators, for example, performance is generally moderately strong with over 15 banks showing strong service for 3 of 4 indicators. Other strong areas include meeting with the bank officer in a private space (21 banks), the tester receiving brochures (18) and the bank officer's business card (19) without asking, the bank officer requesting the purpose (14) and the amount (19) of the loan sought, the officer strongly recommended a particular product (19), and a strong interest in making the loan was conveyed (14).

Against this there are areas of consistently poor service: no banks' officers consistently provided a loan application to the tester without being asked, in no case did the officers consistently offer to help the client complete the loan application, at only two banks did the bank officer consistently ask basic questions about the tester's business. No bank's officers consistently tried to make arrangements for a follow-up contact, and cross selling was extremely weak (discussed further below). Low scores in this area are for whether a SME specialist meet with the client, where only 5 banks showed strong service.

\subsection{Competition}

Two broad competition areas are discussed in this section. First we look at requirements for taking out a loan, including documentation, credit checks and the like. We then turn to differences in the loan products offered.

\subsubsection{Loan requirements}

The first competition area concerns actions by the bank officer that could discourage a client from applying for a loan. In Table 2 we show the results in three areas. The first is whether the tester was told he did not qualify for a loan or that the lender would have to check the firm's credit rating before an application could be taken. In no case was the tester was told that he did not qualify for a loan. Regarding the credit rating, in 6 percent of the cases the bank officer told the tester that an application could not be submitted until after the credit report was obtained.

The second part of the table shows the share of bank officers who told the tester that specific information would be required. Lenders may believe it prudent to require documentation for numerous aspects of a business and its operations. But there is certainly a substantial range among lenders in the number of documents required. Lenders requiring fewer items may be exposing themselves to greater risk but they are clearly making it easier for applicants.

In the table, below the information on specific items, is the distribution of how many type of documentation were listed by each bank officer. The range is remarkable - from none to seven being discussed. The range obviously reflects a combination of the volume of information offered by a bank officer and the lender's actual policies on documentation and other loan conditions. Still, a potential borrower could easily find a long list of requirements 
daunting, particularly if another lender's requirements were much less. By the same token, the borrower could be quite disappointed if he felt he had been misled by a bank officer when he is first told that the requirements are simple only to find they are quite complex when he actually applies for the loan.

Lastly, no bank officer gave the tester an estimate of the size of the loan for which he would likely qualify. Recall that the tester was fully prepared to provide the information necessary for the bank officer to do this. Hence, the finding indicates a lack of follow-up on the officer's part.

\subsubsection{Loan products offered}

A primary competition indicator is the number of products the bank officer described to the tester. About half the time, a single loan product was described to the tester. In another 35 percent of cases, two products were discussed, and in 10 percent of the tests three products. Offering a single loan product could reflect careful thought by the bank officer to align the product with the tester's needs, or it could mean that the officer is selling what he knows best and is easiest for him. The shopper was instructed to ask about a range of products if they were not volunteered by the bank officer. Hence, the evidence suggests that half the branches did not have many alternative products to offer.

The entries in Table 3 illustrate a wide range of products were offered to the tester. The range of interest rate structures is particularly striking, with the structure varying along three dimensions: flat interest calculation versus annuity loans; among annuity loans, those with constant payments and those with declining payments; and, fixed versus variable interest rates. Annuity loans were somewhat more commonly offered as the first product-product " $A$ " in the table--(56 percent versus 44 percent for flat rate loans) and overwhelmingly offered on product B ( 85 versus 15 percent). Annuity interest rate loans offered generally have variable rates but only a few flat rate loans have variable rates.

There is a surprising degree of variation in the interest rates stated to the tester for the same interest rate structure. Among flat rate loans, 15 percent carry rates of 10 percent or less while 15 percent have rates of 30 percent or higher. The spread for annuity loans is tighter, with all rates quoted falling in a 10 to 20 percent range for both products. Some of the greater variation in flat rates may arise from whether rates were quoted in nominal or effective terms. These figures certainly indicate price competition among lenders in the small loan market. (Note 4)

There is substantial variation in other loan characteristics. The tester requested a 5-year loan term and 40 percent of the products offered met this request. Surprisingly, 16 percent of the loans offered had terms of only 1-2 years. Given the impact of the loan term on the size of monthly payments with an annuity loan, the shorter-term products were clearly inferior for our borrower. An important question is whether the short term offered reflects bank policy or a lack of responsiveness by the bank officers.

There is also wide variation in the amount of collateral bank officers indicated would be needed. The most common value quoted was between Rp. 100 and 150 million for the requested Rp. 92 million loan (62 and 89 percent of products A and B, respectively). But 24 percent of bank officers stated requirements would be under Rp. 100 million for product A. Overall, lenders are "collateral lenders" rather than "project lenders." This borne out by both the high collateral requirements and by the fact that only about 7 percent of bank officers told the shopper that cash flow projections would be required as part of the loan application (Tables 2 and 3 ).

It is difficult to picture clearly different loan products based on the kinds of figures presented in Table 3 . To provide greater clarity, Table 4 shows the terms of six specific products discussed with the tester. Each is offered by a different bank. Displayed for three annuity loans and three flat interest rate loans are the interest rate quoted, the loan term (maturity), and collateral the tester was told would be needed. One expects higher interest rates for loans with lower collateral requirements, a fixed versus variable interest rate, and a longer loan term for fixed rate loans. These expectations are generally confirmed in an examination of products.

The range on three loan attributes is wide in Table 4 is wide. Interest rates on flat interest rate structure loans vary from 14 to 24 percent; the 24 percent rate loan has the lowest collateral requirement. For annuity loans, the loan term ranges from 2 to 5 years; and, the required collateral goes from Rp. 100 to 160 million, or 109 to 174 percent of the requested loan amount. The highest collateral loan carries the lowest interest rate and the short loan length. The variable interest rate loan carries a lower interest rate than a fixed rate loan of the same five year maturity. The overall picture is one where a borrower could meet his loan preferences with some comparative shopping.

Loan processing speed is a real issue for smaller firms. Other studies of SME lending have cited micro and small firms placing high value on very quick service, even loan dispersal on the day of application. The last panel of Table 3 gives the distribution of processing times, after a complete application is submitted. The industry standard appears to be two weeks, with this time named in about half of all cases. Interestingly, however, in nearly a quarter of product A cases, times of 0-5 days were offered; and in another quarter of the cases 6-10 days. Again, borrowers have genuine opportunity to tailor a loan package to match their preferences. 


\subsection{Cross Selling}

An important tool for a lender to expand business is by deepening its relationship with clients through inducing clients to use more of its products. Our figures indicate that the lenders tested are doing a poor job in this area. Only 24 percent of bank officers made a serious try to interest the tester in another product, i.e., to cross-sell; and only 10 percent made a strong effort to cross-sell two or more products (last rows in Table 1).

The form completed by the tester after his visit to a lender asked him to distinguish between cases where another product was mentioned or talked about and those where the bank officer made a strong effort to interest him in a product.

Savings accounts were the product most often discussed, but even then only 21 percent of officers talked about it and 16 percent really tried to interest the tester. The parallel figures for credit cards, the second most-often discussed product, are 12 and 8 percent, respectively.

The lack of cross-selling is driven home by the following figures. At the lender level, in half the cases there was no attempt at cross selling at the two branches. Among bank officers, more than 70 percent made no attempt to cross sell.

\section{Conclusions}

We stated earlier that drawing firm conclusions is difficult in this case because of the absence of accepted benchmarks against which we can compare the experience documented for Indonesia through 'mystery shopping.' Nevertheless, some statements seem warranted. First we state conclusions for each of the three areas examined - service quality, competition, and cross-selling. Then a couple of broader points are made.

While there are some bright spots, there is generally room for improvement in service quality. Many improvements could be very easily accomplished, like meeting in a private space, handing out brochures and business cards. These are already standard practice by most branches but should be done by all. They are generally not specific to SME customers and require very little time and effort to fix. Other possible improvements are more difficult to make, such as having SME specialists on hand, but would measurably increase the ability of banks to cater to SME's specifically.

Regarding the degree of competition, there was substantial variation across banks in terms of products offered and loan requirements, but very little variation within a bank branch, i.e., most banks offered just one product to the customer. SMEs in principle have a wide range of products available to them, but they must do their research by visiting or otherwise researching offerings of many banks before they can get a clear picture of possible offers available. This requires time and effort that is in addition to the time it takes wait for a loan to be disbursed. This might lead SME owners to borrow from small informal institutions that can provide very quick service. One response by lenders could be offering more products at each branch to save clients time.

Very little cross-selling is done, indicating a real opportunity for improvements in service. When banks offered a loan to our customer, they often did not offer information on possible alternative loans. Similarly, they did not offer information on alternative products. These appear to be part of a pattern: either bank officers do not think it is worthwhile to provide small business customers with good service and tailored products, or they are offering bad service in general.

Mystery shopping in Jakarta yielded valuable insights for bank managers concerned with the quality of service being provided by their staff. The evidence reviewed here demonstrates that the technique can be employed to assess service offered to small firms and that it may well be advisable for banks seeking to service this market to undertake such performance audits.

\section{Acknowledgements}

Results reported are based on work done for the International Finance Corporation, Jakarta. Thomas Moyes and Nyoman Gde Satrya Wibawa provided useful guidance and excellent comments on this work. The field work was ably executed by Yayasan Inovasi Pemerintahan Daerah (YIPD). None of these organizations or persons bear any responsibility for the contents of this article.

\section{References}

Angur, M.G., R. Nataraajan, and J.S. Jahera, Jr. (1999). Service Quality in the Banking Industry: An Assessment in a Developing Economy, International Journal of Bank Marketing, 17, 3, 116-23.

Asia Foundation. (2005). Indonesia Provincial SME Study. Jakarta: Report to the Asian Development Bank.

Ayyagari, M., Beck, T., and A. Demirguc-Kunt. (2007). Small and Medium Enterprises Across the Globe, Small Business Economics, 29, 415-34.

Bank Indonesia. (2005). Final Report on Research on the Profile of Indonesian Micro, Small and Medium Enterprises. Jakarta: Credit Department, Bank Indonesia. 
Beck, T., and A. Demirguc-Kunt. (2006). Small and Medium-Size Enterprises: Access to Finance as a Growth Constraint, Journal of Banking \& Finance, 30, 2931-43.

Beck, T., A. Demirguc-Kunt, L. Leven, and V. Maksimovic. (2006). The Determinants of Financing Obstacles, Journal of International Money and Finance, 25, 932-52.

Beck, T., A. Demirguc-Kunt, and M.S. Martinez Perla. (2008). Bank Financing of SMEs around the World.: Drivers, Obstacles, Business Models, and Lending Practices. Washington, DC: World Bank Policy Research Working Paper no. 4785 .

Development Alternatives, Inc. (DAI). (2004). Finance for Small and Medium Enterprise in Indonesia: Final Report. Bethesda, MD: Report to Japan Bank for International Cooperation.

Godau, M., W. Hiemann, and S. Jansen. (2004). SME Finance in Indonesia: Fact Finding Mission. Jakarta: Report to KfW-Jakarta Office.

Marshall, K.P., and J.R. Smith, (1999). Race-Ethnic Variations in the Importance of Services Quality Issues in Neighborhood Consumer Banking, Journal of Professional Journal Services Marketing, 18, 2, 119-31.

Newman, K. (2001). Interrogating SERVQUAL: A Critical Assessment of Service Quality Measurement in a High Street Retail Bank, International Journal of Bank Marketing, 19, 3, 126-39.

Newman, K., and A. Cowling. (1996). Service Quality in Retail Banking: The Experience of Two British Clearing Banks, International Journal of Bank Marketing, 14, 6, 3-11.

Parasuraman, A., V.A. Zeithaml, and L.L. Berry. (1988). SERVQUAL: Multiple-Item Scale for Measuring Consumer Perceptions of Service Quality, Journal of Retailing, 64, no.1, 12-40.

Roberts, B., and R.C. Campbell. (2007). Being New-Customer Friendly: Determinants of Service Perceptions in Retail Banking, International Journal of Bank Marketing, 25, 1, 56-67.

Schiffer, M., and B. Weder. (2001). Firm Size and Business Environment: Worldwide Survey Results. Washington, DC: International Finance Corporation Discussion Paper 43.

Schrader, U. (2006). Ignorant Advice—Customer Advisory Service for Ethical Investment Funds, Business Strategy and the Environment, 15, 200-14.

Turner, M.A., F. Freiberg, E. Godfrey, C. Herbig, D.K. Levy, and R.R. Smith. (2002). All Other Things Equal: A Paired Testing Study of Mortgage Lending Institutions. Washington, DC: Urban Institute, Report to the U.S. Department of Housing and Urban Development.

Turner, M.A., and W. Zimmermann. (1994). Acting for the Sake of Research: The Use of Role-Playing in Evaluation, in J.S. Wholely, H. Hatry, and K.E. Newcomer (eds.) Handbook of Practical Program Evaluation. San Francisco: Jossey-Bass.

\section{Notes}

Note 1. The 2006 Economic Survey reports SMEs constituted practically all businesses in the country (99 percent), employed 97 percent of the work force and accounted for 54 percent of that year's GDP. Importantly, the great majority of all firms are micro enterprises - about 82 percent. Small and medium firms account for a significant but much smaller share of firms, specifically 15.8 and 0.6 percent, respectively.

Note 2. SERVQUAL has each respondent fill in form about his or her expectations regarding service (answering yes or no to a set of questions) and then filling in a second form about the actual experience (again usually with yes and no questions). An analysis of the gap between the response sets is then undertaken. Our analysis differs in that where appropriate scoring scales are prepared for the shoppers to guide, with high and low scores definitions given by the project team to ensure consistency in scoring.

Note 3. We did estimate a simple regression model in which the dependent variable is the number of minutes waiting and the independent variables are the number of counters and a dummy variable indicating that the test visited the bank during the peak business period. The result for the visiting-at-peak-times variable is highly statistically significant and indicates that the tester had to wait an additional 6 minutes on average to see a loan officer when he arrived at such a time. The number of counters in the branch was not significant, presumably because there are offsetting effects: there are more counters (less wait time other things equal), but counters are there because there is more business at the bank (more wait time).

Note 4. Another element of price competition is the fees charged that are associated with loan origination. The survey did not gather information on this as part of the 'mystery shopping.' However, the team did make inquiries at four commercial banks about these fees. Consistently, five fees are charged and these are for loan administration, loan provision, notary charge, survey of collateral pledged if needed, and insurance. As a percentage of the INR 92 million loan applied for, charges for the first four fees ranged among the four banks surveyed from 2.6 to 3.3 percent of the 
loan amount. Insurance charges depend on the age of the borrower and the quality of the collateral and could not be readily determined.

Table 1. Service Quality Indicators

\begin{tabular}{|c|c|c|c|c|}
\hline \multirow{2}{*}{\multicolumn{2}{|c|}{ Indicators }} & \multirow[b]{2}{*}{ Mean $^{\mathrm{a}}$} & \multicolumn{2}{|c|}{ \# of Banks with Consistent Service ${ }^{\text {b }}$} \\
\hline & & & Strong Service & Poor Service \\
\hline \multicolumn{5}{|l|}{ Assurance } \\
\hline \multicolumn{2}{|c|}{ Met with loan officer or equivalent } & 0.94 & 24 & 1 \\
\hline \multicolumn{2}{|c|}{ Met with SME specialist } & 0.4 & 5 & 10 \\
\hline \multicolumn{2}{|c|}{ Discussed loan options for which borrower would qualify } & 0.87 & 21 & 2 \\
\hline \multicolumn{2}{|c|}{ Loan Officer had strong knowledge of products } & 0.75 & 16 & 3 \\
\hline \multicolumn{5}{|c|}{ Tangibles } \\
\hline \multicolumn{2}{|c|}{ Meeting with bank officer was in private space } & 0.88 & 21 & 1 \\
\hline \multicolumn{2}{|c|}{ Materials provided } & $--^{\mathrm{e}}$ & -- & -- \\
\hline \multicolumn{2}{|c|}{ Obtained brochures of information on loan products without asking } & 0.83 & 18 & 1 \\
\hline \multicolumn{2}{|c|}{ Obtained loan application without asking } & 0.13 & 0 & 19 \\
\hline \multicolumn{2}{|c|}{ Obtained credit simulation without asking } & 0.62 & 11 & 5 \\
\hline $\begin{array}{l}\text { Number of loan offi } \\
\qquad \begin{array}{l}\text { Distribution } \\
0 \text { Counters } \\
1 \\
2-3 \\
4 \text { and up }\end{array}\end{array}$ & 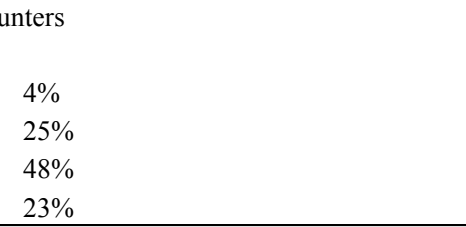 & 2.71 & -- & -- \\
\hline & \multicolumn{3}{|c|}{ Empathy } \\
\hline $\begin{array}{l}\text { Time client waited } \mathrm{t} \\
\text { Distribution } \\
0 \text { Minutes } \\
1-5 \\
6-10 \\
11 \text { and up }\end{array}$ & $\begin{array}{l}\text { Dank officer }{ }^{\mathrm{c}} \text { (minutes) } \\
10 \% \\
46 \% \\
27 \% \\
17 \% \\
\end{array}$ & 6.63 & 5 & 8 \\
\hline $\begin{array}{l}\text { 18-25 Minutes } \\
26-35 \\
36-45 \\
46 \text { and up } \\
\end{array}$ & $\begin{array}{l}\text { officer }^{\mathrm{d}} \text { (minutes) } \\
\\
29 \% \\
37 \% \\
29 \% \\
6 \% \\
\end{array}$ & 32.92 & 10 & 11 \\
\hline \multicolumn{2}{|l|}{ Welcome provided } & 0.96 & 24 & 0 \\
\hline \multicolumn{2}{|c|}{ Bank officer offered to help complete application } & 0.04 & 0 & 24 \\
\hline \multicolumn{2}{|c|}{ Obtained business card or contact information without asking } & 0.81 & 19 & 3 \\
\hline Bank officer was re & endly & 0.71 & 13 & 2 \\
\hline Responsiveness & & & & \\
\hline Loan officer request & imated loan amount & 0.81 & 19 & 3 \\
\hline Loan officer asked $\mathrm{p}$ & e of loan & 0.77 & 14 & 0 \\
\hline Loan officer asked a & asic business information & 0.19 & 2 & 18 \\
\hline One or more loan pr & s disparaged & 0.08 & 1 & 23 \\
\hline One product was str & recommended & 0.77 & 19 & 5 \\
\hline Asked to complete a & application & 0.1 & 1 & 22 \\
\hline Bank officer tried to & arrangement for future contact & 0 & 0 & 25 \\
\hline Strong interest in $\mathrm{m}$ & the loan was conveyed & 0.67 & 14 & 5 \\
\hline Loan officer tried he & sell at least one additional product & 0.24 & 2 & 15 \\
\hline Loan officer tried he & sell 2 or more additional products & 0.1 & 1 & 21 \\
\hline
\end{tabular}

a. For values from 52 tests.

b. "Strong service" indicates that in both tests the findings were consistent with good practice as defined herein; "poor service" indicates findings were consistently out of line with good practice.

c. "Strong service" means time waiting was less than the median value for all interviews.

d. "Strong service" means time with bank staff was greater than the median time for all interviews.

e. Not applicable. 
Table 2. Competition: Rejection and Eligibility Screens

\begin{tabular}{|c|c|c|c|}
\hline \multicolumn{2}{|c|}{ Description } & Mean & $\mathbf{N}$ \\
\hline \multicolumn{4}{|l|}{ Rejection } \\
\hline \multicolumn{2}{|c|}{ Respondent not qualified for any type of financing } & 0 & 51 \\
\hline \multicolumn{2}{|c|}{ No discussion of loan before a credit check conducted } & 0.06 & 52 \\
\hline \multicolumn{4}{|c|}{ Eligibility Screens / Loan Requirements } \\
\hline \multirow{2}{*}{\multicolumn{2}{|c|}{$\begin{array}{l}\text { Mean number of eligibility screens/ loan requirements from list below } \\
\text { discussed } \\
\text { Distribution }\end{array}$}} & 5.69 & 52 \\
\hline & & & \\
\hline 0 & $4 \%$ & & \\
\hline $1-4$ & $17 \%$ & & \\
\hline $5-6$ & $35 \%$ & & \\
\hline 7 & $44 \%$ & & \\
\hline \multicolumn{2}{|c|}{ Incidence of main loan requirements discussed: } & & \\
\hline \multicolumn{2}{|c|}{ NPWP (tax ID) } & 0.77 & 52 \\
\hline \multicolumn{2}{|l|}{ Business license document } & 0.94 & 52 \\
\hline \multicolumn{2}{|l|}{ Land and building tax } & 0.81 & 52 \\
\hline \multicolumn{2}{|l|}{ Collateral generally } & 0.92 & 52 \\
\hline \multicolumn{2}{|l|}{ Company location and buildings } & 0.73 & 52 \\
\hline \multicolumn{2}{|l|}{ Bank account } & 0.87 & 52 \\
\hline \multicolumn{2}{|c|}{ Income statement and/or balance sheet } & 0.65 & 52 \\
\hline \multicolumn{2}{|c|}{ Other } & 0.52 & 52 \\
\hline \multicolumn{4}{|l|}{ Distribution } \\
\hline Electricity Payment & $44 \%$ & & 27 \\
\hline Build Drawing & $22 \%$ & & 27 \\
\hline Company Profile & $22 \%$ & & 27 \\
\hline Projected Cash Flow & $7 \%$ & & 27 \\
\hline Supplier List & $7 \%$ & & 27 \\
\hline \multicolumn{2}{|l|}{ None were discussed } & 0 & 52 \\
\hline \multicolumn{4}{|l|}{ Loan value } \\
\hline \multicolumn{2}{|c|}{ Client was told the loan value for which he would qualify } & 0 & 49 \\
\hline
\end{tabular}


Table 3. Loan Products Offered

\begin{tabular}{|c|c|c|c|c|}
\hline Loan Characteristic & Product A & $\mathbf{N}$ & Product B & $\mathbf{N}$ \\
\hline Mean interest rate quoted & 17.44 & 47 & 15.26 & 21 \\
\hline \multicolumn{5}{|l|}{ Interest Rate Structure } \\
\hline Flat & 0.44 & 48 & 0.15 & 20 \\
\hline Fixed & 0.95 & 21 & 0.33 & 3 \\
\hline Not Fixed & 0.05 & 21 & 0.67 & 3 \\
\hline Annuity & 0.56 & 48 & 0.85 & 20 \\
\hline Constant Payment & 0.74 & 27 & 0.47 & 17 \\
\hline Fixed & 0.20 & 20 & 0 & 8 \\
\hline Not Fixed & 0.80 & 20 & 1.00 & 8 \\
\hline Declining Payment & 0.26 & 27 & 0.53 & 17 \\
\hline Fixed & 0.29 & 7 & 0.33 & 9 \\
\hline Not Fixed & 0.71 & 7 & 0.67 & 9 \\
\hline \multicolumn{5}{|l|}{ Interest Rates } \\
\hline \multicolumn{5}{|l|}{ Flat } \\
\hline Mean & 20.68 & 20 & 15.33 & 3 \\
\hline Min & 6 & 20 & 13 & 3 \\
\hline Max & 33 & 20 & 19 & 3 \\
\hline \multicolumn{5}{|l|}{ Distribution } \\
\hline $1-10$ & 0.15 & 20 & 0 & 3 \\
\hline $10.1-20$ & 0.25 & 20 & 1.00 & 3 \\
\hline 20.1-30 & 0.45 & 20 & 0 & 3 \\
\hline 30.1 and up & 0.15 & 20 & 0 & 3 \\
\hline \multicolumn{5}{|l|}{ Annuity } \\
\hline Mean & 15.0 & 27 & 15.2 & 17 \\
\hline Min & 11.5 & 27 & 11.5 & 17 \\
\hline Max & 18.8 & 27 & 18.0 & 17 \\
\hline \multicolumn{5}{|l|}{ Distribution } \\
\hline $1-10$ & 0 & 27 & 0 & 17 \\
\hline $10.1-15$ & 0.70 & 27 & 0.47 & 17 \\
\hline $15.1-20$ & 0.30 & 27 & 0.53 & 17 \\
\hline Interest rate is fixed for life of loan? & 0.54 & 48 & 0.18 & 21 \\
\hline \multicolumn{5}{|l|}{ Length of Loan ${ }^{\mathrm{a}}$} \\
\hline 1 year & 0.06 & 48 & 0.1 & 21 \\
\hline 2 years & 0.10 & 48 & 0.19 & 21 \\
\hline 3 years & 0.38 & 48 & 0.29 & 21 \\
\hline 4 years & 0.06 & 48 & 0 & 21 \\
\hline 5 years & 0.40 & 48 & 0.43 & 21 \\
\hline Incentive rebated for on-time payment? & 0 & 47 & 0 & 21 \\
\hline \multicolumn{5}{|l|}{ Distribution } \\
\hline $0-100$ & 0.24 & 45 & 0.05 & 19 \\
\hline $101-150$ & 0.62 & 19 & 0.89 & 19 \\
\hline 151 and up & 0.13 & 19 & 0.05 & 19 \\
\hline Mean processing time after application is submitted (days) & 10.69 & 48 & 12.6 & 20 \\
\hline \multicolumn{5}{|l|}{\begin{tabular}{|l|l} 
Distribution &
\end{tabular}} \\
\hline$\underline{0-5}$ days & 0.23 & 48 & 0.05 & 20 \\
\hline $6-10$ & 0.27 & 48 & 0.25 & 20 \\
\hline $11-15$ & 0.44 & 48 & 0.65 & 20 \\
\hline 16 and up & 0.06 & 48 & 0.05 & 20 \\
\hline
\end{tabular}

a. 5-year loan term was requested.

b. Loan amount requested was Rp. $92 \mathrm{mln}$. 
Table 4. Six Sample Loan Products

\begin{tabular}{|l|lll|lll|}
\hline & \multicolumn{3}{|l|}{ Annuity loans } & Flat rate loans \\
\hline Interest rate fixed (Y/N) & $\mathrm{N}$ & $\mathrm{Y}$ & $\mathrm{Y}$ & $\mathrm{Y}$ & $\mathrm{N}$ & $\mathrm{Y}$ \\
Interest rate & 15 & 18 & 11.5 & 20.4 & 14 & 24 \\
Loan term (years) & 5 & 5 & 2 & 4 & 3 & 2 \\
Collateral required (Rp. mln) & 115 & 100 & 160 & 143 & 150 & 75 \\
\hline
\end{tabular}

